Osmanen und Islam

in Südosteuropa 


\section{Abhandlungen der Akademie der Wissenschaften zu Göttingen}

Neue Folge, Band 24

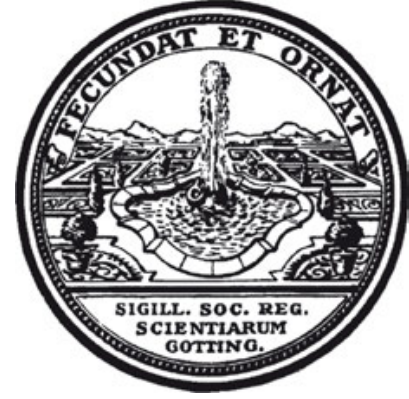

De Gruyter 


\title{
Osmanen und Islam in Südosteuropa
}

\author{
Herausgegeben von \\ Reinhard Lauer und Hans Georg Majer
}

Redaktion
Natalya Maisheva und Aleksandra Laski

De Gruyter 


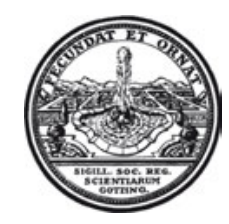

Vorgelegt von Reinhard Lauer in der Sitzung vom 18. Oktober 2011

\author{
ISBN 978-3-11-025133-3 \\ e-ISBN 978-3-11-026059-5 \\ ISSN 0930-4304
}

Library of Congress Cataloging-in-Publication Data:

A CIP catalog record for this book has been applied for at the Library of Congress

Bibliografische Information der Deutschen Nationalbibliothek

Die Deutsche Nationalbibliothek verzeichnet diese Publikation in der Deutschen Nationalbibliografie; detaillierte bibliografische Daten sind im Internet über http://dnb.dnb.de abrufbar.

(C) 2014 Walter de Gruyter GmbH, Berlin/Boston

Satz: Michael Peschke, Berlin

Druck: Hubert \& Co. GmbH \& Co. KG, Göttingen

(๖) Gedruckt auf säurefreiem Papier

Printed in Germany

www.degruyter.com 